\title{
Efeito fungitóxico de óleos essenciais sobre Colletotrichum gloeosporioides, isolado do maracujazeiro amarelo
}

\author{
Ismail Teodoro Souza Júnior ${ }^{1 *}$ \\ Nilza Lima Pereira Sales ${ }^{2}$ \\ Ernane Ronie Martins ${ }^{2}$ \\ ${ }^{1}$ Departamento de Fitossanidade, FAEM, Universidade Federal de Pelotas \\ CEP 96010-970, Pelotas - RS, Brasil \\ ${ }^{2}$ Instituto de Ciências Agrárias, Universidade Federal de Minas Gerais - UFMG \\ *Autor para correspondência \\ agrojunior1@yahoo.com.br
}

Submetido em 31/10/2008

Aceito em 17/03/2009

\section{Resumo}

O presente trabalho objetivou avaliar o efeito de diferentes concentrações de óleos essenciais sobre o fungo Colletotrichum gloeosporioides. Os óleos essenciais foram obtidos a partir da parte aérea das plantas Lippia sidoides, Ocimum gratissimum, Lippia citriodora, Cymbopogon citratus e Psidium guayava var. pomifera. Após a incorporação dos óleos em meio ágar-água e BDA (batata, dextrose e ágar), nas concentrações de $1 \mu \mathrm{L} /$ $\mathrm{mL}, 3 \mu \mathrm{L} / \mathrm{mL} 5 \mu \mathrm{L} / \mathrm{mL}$ e $10 \mu \mathrm{L} / \mathrm{mL}$ e a testemunha a $0 \mu \mathrm{L} / \mathrm{mL}$ (óleo/meio de cultura), avaliou-se a inibição da germinação dos conídios e a inibição do crescimento micelial, respectivamente. Os resultados demonstraram que a partir da concentração de $1 \mu \mathrm{L} / \mathrm{mL}$, os óleos essenciais de todas as espécies vegetais tiveram efeito sobre a germinação dos conídios, com inibição de 100\%. As espécies Lippia sidoides, Ocimum gratissimum, Lippia citriodora, Cymbopogon citratus inibiram em 100\% o crescimento micelial do fungo. O óleo da Psidium guayava var. pomifera mostrou inibição crescente sobre o micélio do C. gloeosporioides com o aumento das concentrações desse óleo essencial.

Unitermos: controle alternativo de doenças, crescimento micelial, germinação de conídios

\section{Abstract}

Fungitoxic effect of concentrations of essential oils on Colletotrichum gloeosporioides, isolated from the passion fruit. This study aimed to evaluate the effect of different concentrations of essential oils on the fungus Colletotrichum gloeosporioides. The essential oils were obtained from shoots of the plants Lippia sidoides, Ocimum gratissimum, Lippia citriodora, Cymbopogon citratus and Psidium guayava var. pomifera. After the incorporation of oil in water-agar and PDA medium, in concentrations of $1 \mu \mathrm{L} / \mathrm{mL}, 3 \mu \mathrm{L} / \mathrm{mL} 5 \mu \mathrm{L} / \mathrm{mL}$ and $10 \mu \mathrm{L} /$ $\mathrm{mL}$ and witness at $0 \mu \mathrm{L} / \mathrm{mL}$ (oil/the culture medium), the inhibitions of conidia germination and mycelial growth, respectively, were evaluates. The results showed that from the concentration of $1 \mu \mathrm{L} / \mathrm{mL}$, essential oils of all plant species had an effect on conidia germination, with an inhibition of $100 \%$. The species Lippia sidoides, Ocimum gratissimum, Lippia citriodora and Cymbopogon citratus inhibited the growth of the fungus mycelium by $100 \%$. The oil of Psidium guayava var. pomifera had progressive control over the mycelium of C. gloeosporioides, in accordance with the increase in concentrations of essential oil.

Key words: alternative control of diseases, germination of spores, mycelial growth 


\section{Introdução}

$\mathrm{O}$ maracujazeiro amarelo (Passiflora edulis $\mathrm{f}$. flavicarpa Deg.), é uma planta originária da América Tropical, se adaptou muito bem às condições de ambiente do Brasil. Sendo este, atualmente, o primeiro produtor mundial, seguido do Peru, Venezuela, África do Sul, Sri Lanka e Austrália (Viana et al., 2003).

As plantas de maracujá podem ser afetadas por várias doenças causadas por fungos, bactérias, vírus e nematóides. Dentre as doenças fúngicas que ocorrem na parte aérea, pode-se citar a antracnose, verrugose, mancha de Alternaria e mancha de Septoria. A antracnose é causada pelo fungo Colletotrichum gloeosporioides Penz e sua forma perfeita Glomerella cingulata (Stonem.) Spaud \& Schrenk, constitui-se em uma das doenças de maior expressão econômica para a cultura do maracujazeiro amarelo. A sua ocorrência dá-se praticamente em todas as regiões produtoras no Brasil e também em diversos países. Ataca todos os órgãos aéreos da planta como folhas, botões florais, gavinhas, ramos e frutos (Ruggiero, 1998).

Doenças em plantas têm contribuído significativamente na redução da produção e do fornecimento de alimentos à população. Assim sendo, a utilização do manejo ecológico de doenças é preconizada com o objetivo de reduzir o uso de fungicidas, uma vez que estes causam danos ao homem e o meio ambiente (Talamini e Stadnick, 2004). O uso indiscriminado de agrotóxicos provoca o acúmulo de substâncias nocivas no solo e na água, leva o surgimento de populações de fitopatógenos resistentes aos compostos químicos além do desequilíbrio ambiental, pela falta de seletividade dos produtos utilizados. O registro do aumento no consumo de agrotóxicos foi de $276,2 \%$ no período compreendido entre 1964 e 1991, comportamento esse não associado à expansão da área cultivada (Campanhola, 2003), sugere a busca de ferramentas efetivas e economicamente viáveis de controle de doenças em plantas.

Importante preocupação se deve ter também em relação aos produtores orgânicos, os quais não possuem muitas alternativas para o controle de doenças, uma vez que a grande maioria dos produtos não pode ser utilizada. Aliado a esses fatos, atualmente com o crescimento da exigência dos consumidores por alimentos livres de agrotóxicos, várias pesquisas estão sendo realizadas voltadas para a busca de produtos fitossanitários naturais. Os óleos essenciais vegetais são considerados fontes para o desenvolvimento desses novos produtos naturais. Entretanto, sabe-se que grande parte da flora brasileira ainda não foi estudada, sendo a descoberta de novos compostos químicos, a partir de plantas, capazes de controlar o desenvolvimento de fitopatógenos, de grande importância (Stangarlin et al., 1999).

A utilização de produtos naturais no controle de doenças de plantas tem se tornado um meio eficiente para a redução do uso indiscriminado de defensivos. A exploração da atividade biológica dos metabólitos secundários dos extratos brutos e dos óleos essenciais de plantas surge como uma forma potencial de controle alternativo de doenças das plantas cultivadas. Vários extratos brutos e óleos essenciais de plantas já foram testados sobre fungos fitopatogênicos em diversos trabalhos (Takatsuka et al., 2003; Balbi-Peña et al., 2006; Pereira et al., 2006).

Diante do exposto, o presente trabalho objetivou avaliar o efeito direto do óleo essencial de alecrimpimenta (Lippia sidoides Cham.), alfavaca-cravo (Ocimum gratissimum L.), capim-santo (Cymbopogon citratus Stapf.), cidrão (Lippia citriodora Kunth.), e goiabeira vermelha (Psidium guayava var. pomifera L.) sobre a germinação dos conídios e sobre o crescimento micelial do fungo Colletotrichum gloeosporioides, buscando-se as concentrações inibitórias mínimas (CIM).

\section{Material e Métodos}

\section{Isolamento do patógeno}

O fungo $C$. gloeosporioides foi isolado a partir de folhas de maracujazeiro, apresentando sintomas típicos da doença. Pedaços de tecido foliar de $0,5 \mathrm{~mm}$ de diâmetro foram retirados de lesões, na região entre $\mathrm{a}$ área lesionada e a área sadia. Esses fragmentos foram superficialmente desinfetados com álcool $70 \%$ durante 30 segundos e hipoclorito de sódio $2,0 \%$ durante 30 segundos e enxaguados três vezes em água destilada 
estéril. Em seguida, estes pedaços de tecido foram transferidos para placas de Petri contendo meio de cultura BDA (batata, dextrose e ágar) sendo incubadas por 15 dias, sob fotoperíodo de $12 \mathrm{~h}$ e temperatura de $25^{\circ} \mathrm{C}$, em estufa incubadora. Após esse período, discos de $0,5 \mathrm{~mm}$ foram retirados dos bordos das colônias e transferidos para tubos contendo meio de BDA. A manutenção dos isolados foi realizada pelo armazenamento dos tubos em geladeira a $5^{\circ} \mathrm{C}$ (Ribeiro e Bedendo, 1999).

\section{Obtenção dos óleos essenciais}

Para a obtenção dos óleos essenciais vegetais, foram utilizadas folhas frescas de alecrim-pimenta (Lippia sidoides Cham.), alfavaca-cravo (Ocimum gratissimum L.), capim-santo (Cymbopogon citratus Stapf), cidrão (Lippia citriodora Kunth.), e goiaba vermelha (Psidium guayava var. pomifera L.). Para a extração dos óleos essenciais foi empregado o aparelho de Clevenger, utilizando o método de hidrodestilação por arraste com vapor d'água (Craveiro et al., 1981). Foram utilizadas $150 \mathrm{~g}$ da parte aérea de cada espécie vegetal, que foram colocadas em balão de vidro, cobrindo com água destilada até $2 / 3$ do balão. $O$ tempo para o processo de extração dos óleos foi de $3 \mathrm{~h}$ ininterruptas, sendo que, ao final, o óleo foi separado da água por separação líquidolíquido. Decorrido esse tempo, os óleos essenciais foram armazenados em frascos no freezer.

\section{Determinação das concentrações de óleos essenciais sobre a germinação dos conídios}

A atividade antifúngica das diferentes concentrações dos óleos essenciais foi avaliada microscopicamente, pela observação por meio da inibição da germinação dos conídios do fungo. A suspensão de conídios foi obtida adicionando-se água destilada estéril às culturas fúngicas em placas de Petri e, posteriormente, filtrandose esse conteúdo em gaze. A concentração de esporos dessa suspensão foi determinada com auxilio de hemacitômetro (câmara de Neubauer) e ajustada para $2 \times 10^{5}$ conídios. $\mathrm{mL}^{-1}$.

As concentrações utilizadas de cada um dos óleos foram $1 \mu \mathrm{L} / \mathrm{mL}, 3 \mu \mathrm{L} / \mathrm{mL}, 5 \mu \mathrm{L} / \mathrm{mL}$ e $10 \mu \mathrm{L} / \mathrm{mL}$ em meio ágar-água, sendo que a testemunha consistiu apenas de placas contendo apenas o meio. Os óleos essenciais foram adicionados ao meio ágar-água a $45^{\circ} \mathrm{C}$ e em seguida vertidos em placa de Petri, onde, imediatamente após, foi adicionado $500 \mu \mathrm{L}$ da suspensão de conídios. As placas foram incubadas sob fotoperíodo de $9 \mathrm{~h}$ e temperatura de $25^{\circ} \mathrm{C}$. A avaliação foi realizada determinando-se a porcentagem de germinação de 100 esporos, nove horas após o início da incubação, contando-se o número de esporos germinados e não germinados ao microscópio óptico em três diferentes pontos da placa de Petri, no aumento de 40x no microscópio. O ensaio foi conduzido em delineamento inteiramente casualizado em esquema fatorial $5 \times 5$ (cinco óleos essenciais $x$ cinco concentrações), com quatro repetições (Silva e Bastos, 2007).

\section{Determinação das concentrações de óleos essenciais sobre o crescimento micelial do fungo}

A atividade antifúngica das concentrações dos óleos essenciais foi avaliada através da inibição do crescimento miceliano do patógeno. Utilizaram-se cada óleo essencial das espécies vegetais nas concentrações de $1 \mu \mathrm{L} / \mathrm{mL}, 3 \mu \mathrm{L} / \mathrm{mL}, 5 \mu \mathrm{L} / \mathrm{mL}$ e $10 \mu \mathrm{L} / \mathrm{mL}$ em meio de cultura BDA. A testemunha consistiu do disco do fungo cultivado em meio BDA. O ensaio foi conduzido em delineamento inteiramente casualizado, em esquema fatorial 5x5 (cinco plantas $\mathrm{x}$ cinco concentrações). Para cada tratamento óleo/concentração foram empregadas quatro repetições.

Desta forma, o óleo essencial das plantas foi primeiramente adicionado ao meio BDA fundente com temperatura máxima de $45^{\circ} \mathrm{C}$, e em seguida vertido em placas de Petri de $9 \mathrm{~cm}$ de diâmetro. Cada placa foi inoculada, no centro, com um disco de $5 \mathrm{~mm}$ de diâmetro, contendo micélios da cultura monospórica (Grigoletti Júnior e Lau, 1999). As placas foram incubadas à temperatura de $25^{\circ} \mathrm{C}$ sob fotoperíodo de $12 \mathrm{~h}$. A avaliação do efeito das diferentes concentrações de óleo essencial sobre o crescimento miceliano foi realizada quando o crescimento miceliano da testemunha cobriu totalmente a superfície do meio de cultura. A leitura do experimento foi feita medindo-se o diâmetro da área de crescimento 
miceliano em dois eixos ortogonais (média das duas medidas diametricamente opostas). Com a média dos resultados obtidos foi determinada a ação fungitóxica dos óleos através da concentração inibitória mínima (CIM), expressa em microlitros por mililitros $(\mu \mathrm{L} / \mathrm{mL})$, que representa a mais baixa concentração necessária para causar total inibição do crescimento micelial dos fungos (Silva e Bastos, 2007).

Foram realizadas avaliações, calculando-se a porcentagem de inibição do crescimento dos tratamentos em relação à testemunha, utilizando-se a fórmula:

$$
\mathrm{PIC}=\frac{(\text { diâmetro da test }- \text { diâmetro do trat }) \times 100}{\text { diâmetro da test }}
$$

Onde:

Diâmetro da test $=$ diâmetro da testemunha

Diâmetro do trat $=$ diâmetro do tratamento

Os dados obtidos nesse estudo foram submetidos à análise de variância, e as médias comparadas pelo teste de Tukey a $5 \%$ de probabilidade sendo esta realizada utilizando-se o programa SASM-Agri ${ }^{\circledR}$ (Canteri et al., 2001).

\section{Resultados e Discussão}

\section{Efeito das concentrações de óleos es- senciais sobre a germinação de espo- ros do fungo C. gloeosporioides}

Os resultados observados mostraram que todos os óleos essenciais e todas as concentrações testadas inibiram em $100 \%$ a germinação dos esporos de $C$. gloeosporioides (Tabela 1). Sete dias após a avaliação, verificou-se que os esporos permaneceram sem germinar, não ocorrendo, conseqüentemente, o crescimento micelial do fungo e, comprovando-se, portanto, o efeito fungicida dos óleos essenciais e não somente fungistático.

Esses resultados podem ter sido influenciados pela presença de vários compostos com ação antimicrobiana. As folhas de alfavaca-cravo apresentam 3,6\% de óleo essencial, sendo que $73,3 \%$ é eugenol, $12,1 \%$ de 1,8 cineol, $2,3 \%$ de $\beta$-cariofileno, 2,1\% de (Z)-ocimeno (Lorenzi, 2002). O óleo de alecrim-pimenta possui como principal componente o timol (60\%), que tem conhecida ação bactericida e antimicótica (Goodman e Gilman, 1978). O óleo essencial presente nas folhas de goiabeira é rico em bisaboleno e outros sesquirtepenos, além de acetais dietoximetano e dietoxietano que dão o aroma aos frutos (Lorenzi, 2002). O óleo essencial de cidrão contém geraniol, citral, mirceno, dentre outros (Martins et al., 2002).

TABELA 1: Porcentagem de germinação dos conídios de Colletotrichum gloeosporioides com diferentes concentrações dos óleos essenciais de diferentes espécies vegetais.

\begin{tabular}{lcccccc}
\hline \multirow{2}{*}{ Óleos essenciais } & \multicolumn{6}{c}{ Concentração $\boldsymbol{\mu L} / \mathbf{m L}$} \\
\cline { 2 - 6 } & $\mathbf{0}$ & $\mathbf{1}$ & $\mathbf{3}$ & $\mathbf{5}$ & $\mathbf{1 0}$ \\
\hline Alecrim-pimenta & $0 \mathrm{~b}$ & $100 \mathrm{a}$ & $100 \mathrm{a}$ & $100 \mathrm{a}$ & $100 \mathrm{a}$ \\
Alfavaca-cravo & $0 \mathrm{~b}$ & $100 \mathrm{a}$ & $100 \mathrm{a}$ & $100 \mathrm{a}$ & $100 \mathrm{a}$ \\
Capim-santo & $0 \mathrm{~b}$ & $100 \mathrm{a}$ & $100 \mathrm{a}$ & $100 \mathrm{a}$ & $100 \mathrm{a}$ \\
Cidrão & $0 \mathrm{~b}$ & $100 \mathrm{a}$ & $100 \mathrm{a}$ & $100 \mathrm{a}$ & $100 \mathrm{a}$ \\
Goiaba & $0 \mathrm{~b}$ & $100 \mathrm{a}$ & $100 \mathrm{a}$ & $100 \mathrm{a}$ & $100 \mathrm{a}$ \\
\hline
\end{tabular}

*Médias seguidas da mesma letra nas linhas não diferem entre si pelo teste Tukey a $5 \%$ de probabilidade

Trabalhos relatando o efeito de óleos essenciais de plantas sobre a germinação de esporos de espécies do gênero Colletotrichum, bem como as concentrações mínimas inibitórias ao fungo, são escassos na literatura. Bastos e Albuquerque (2004), testando o óleo essencial de pimenta-de-macaco (Piper aduncum) sobre os conídios de C. musae, observaram $100 \%$ de inibição da germinação dos esporos utilizando concentrações do óleo acima de $100 \mu \mathrm{g} / \mathrm{mL}$.

Pesquisas recentes, sobre o efeito de diferentes concentrações de óleos essenciais em outros patossistemas foram realizadas. Silva e Bastos (2007), avaliando in vitro, a atividade fungitóxica de diferentes concentrações do óleo essencial extraído de dez espécies de Piper coletadas na região Amazônica, encontraram $100 \%$ de inibição na germinação de basidiósporos de Crinipellis perniciosa, agente causal da vassoura-de-bruxa do cacaueiro. A inibição total da germinação foi observada para os óleos de $P$. dilatatum, $P$. callosum e $P$. marginatum var. anisatum, nas concentrações de $0,4,0,5$ e $0,5 \mu \mathrm{L} / \mathrm{mL}$ em meio BDA, respectivamente. Medice et al. (2007), observaram que os óleos essenciais de eucalipto citriodora (Corymbia 
citriodora), citronela (Cymbopogon nardus), nim (Azadirachta indica) e tomilho (Thymus vulgaris) nas concentrações $1 \%, 0,5 \%, 1,0 \%$ e $0,3 \%$ respectivamente, inibiram em $100 \%$ a germinação dos uredinósporos de Phakospsora pachyrhizi, agente causal da ferrugem da soja, em meio água-ágar.

Em experimento realizado por Salustiano et al. (2006), onde foi avaliada a atividade de extratos de folhas e do óleo essencial da candeia (Eremanthus erythopappus) sobre a germinação de uredinósporos de ferrugens, Puccinia psidii, Hemileia vastatrix, Phakopsora pachyrhizi, e Cerotelium fici e sobre o crescimento micelial de Cilindrocladium scoparium, os autores verificaram que urediniósporos de todas as ferrugens não germinaram quando submetidos ao tratamento. Foi observado também, inibição de 52\% do crescimento micelial de C. scoparium com uso de extrato metanólico, com conseqüente redução da produção de esporos. Ambos os tratamentos, infusão a $10 \%$ e óleo essencial a $1 \%$, reduziram em $25 \%$ o crescimento micelial do fungo, reduziram em $28 \%$ e $34 \%$, respectivamente, a produção de esporos.

Os óleos essenciais de Cymbopogom citratus, Eucalyptus citriodora e Ageratum conyzoides inibiram completamente a germinação de esporos do fungo Dydimella bryoniae, causador de danos às folhas e frutos de melão (Fiori, 2000).

No trabalho realizado por Pereira (2006), onde foi avaliado o efeito de diferentes doses do óleo essencial de tomilho na germinação de Cercospora coffeicola, causador da cercosporiose do café, e os autores observaram que o óleo essencial apresentou efeito tóxico aos conídios, nas concentrações de 500, 1000 e 2000 ppm, com redução na germinação de $27 \%, 30 \%$ e $45 \%$, respectivamente.

Efeito das concentrações de óleos essenciais sobre o crescimento micelial do Colletotrichum gloeosporioides in vitro

Todas as concentrações dos óleos essenciais das espécies vegetais analisadas exerceram inibição do crescimento micelial do fungo a partir da concentração $1 \mu \mathrm{L} / \mathrm{mL}$. Os óleos essenciais da maioria das plantas nas concentrações testadas inibiram o crescimento micelial em $100 \%$ comparando-se com a testemunha $(0 \mu \mathrm{L} / \mathrm{mL})$ (Tabela 2).

O óleo de goiaba vermelha foi o único que mostrou inibição crescente do micélio de C. gloesporioides, conforme o aumento das concentrações do mesmo, apesar de não ter diferido entre si, pelo teste Tukey a $5 \%$ de probabilidade (Tabela 2 ).

Os óleos utilizados neste trabalho já foram testados em outros trabalhos, onde também foi demonstrado o seu potencial. Pessoa et al. (1996), utilizando o óleo essencial de alecrim-pimenta a 10\%, observou inibição do crescimento micelial dos fungos Macrophomina phaseolina, Fusarium oxysporum, Colletotrichum gloesporioides e Rhizopus sp. em testes in vitro. Em outro trabalho Vivas et al. (2006) constataram que o efeito do óleo essencial de capim-santo promoveu inibição em $100 \%$ do crescimento micelial do fungo Colletotrichum acuntatum, nas concentrações superiores a $100 \mu \mathrm{L} / \mathrm{mL}$.

TABELA 2: Porcentagem de inibição do crescimento miceliano de C. gloeosporioides com diferentes concentrações de óleos essenciais de diferentes espécies vegetais

\begin{tabular}{lccccc}
\hline \multirow{2}{*}{ Óleos essenciais } & \multicolumn{5}{c}{ Concentração $\boldsymbol{\mu L} / \mathbf{m L}$} \\
\cline { 2 - 6 } & $\mathbf{0}$ & $\mathbf{1}$ & $\mathbf{3}$ & $\mathbf{5}$ & $\mathbf{1 0}$ \\
\hline Alecrim-pimenta & $0 \mathrm{~b}$ & $100 \mathrm{a}$ & $100 \mathrm{a}$ & $100 \mathrm{a}$ & $100 \mathrm{a}$ \\
Alfavaca-cravo & $0 \mathrm{~b}$ & $100 \mathrm{a}$ & $100 \mathrm{a}$ & $100 \mathrm{a}$ & $100 \mathrm{a}$ \\
Capim-santo & $0 \mathrm{~b}$ & $100 \mathrm{a}$ & $100 \mathrm{a}$ & $100 \mathrm{a}$ & $100 \mathrm{a}$ \\
Cidrão & $0 \mathrm{~b}$ & $100 \mathrm{a}$ & $100 \mathrm{a}$ & $100 \mathrm{a}$ & $100 \mathrm{a}$ \\
Goiaba & $0 \mathrm{~b}$ & $44 \mathrm{a}$ & $50 \mathrm{a}$ & $67 \mathrm{a}$ & $69 \mathrm{a}$ \\
\hline
\end{tabular}

*Médias seguidas da mesma letra nas linhas não diferem entre si pelo teste Tukey a $5 \%$ de probabilidade.

O efeito de alguns dos óleos utilizados nesse trabalho também já foi observado sobre o crescimento micelial de C. gloeosporioides por outros autores, como Guimarães et al. (2007), que avaliaram o efeito do óleo essencial de capim-santo e de seus componentes (citral e mirceno). A concentração mínima inibitória encontrada foi de 500ppm, para o óleo essencial e também para o citral, inibindo em $100 \%$ o crescimento micelial 
do fungo. No entanto, observou-se que o mirceno apresentou baixa atividade, onde, na concentração500 ppm, foi observada inibição de apenas $22,17 \%$ do crescimento micelial. Comprovou-se desta forma, que o efeito fungitóxico do óleo essencial se deu pela ação do componente citral.

Pereira et al. (2007), testando diferentes concentrações de óleo essencial de C. citratus e $E$. citriodora sobre os fungos C. musae e C. gloeosporioides, causadores da podridão da banana, encontraram inibição em $100 \%$ do crescimento micelial do C. gloeosporioides na concentração de $1000 \mu \mathrm{L} / \mathrm{L}$ a $1500 \mu \mathrm{L} / \mathrm{L}$ e do C. musae na concentração de $1500 \mu \mathrm{L} / \mathrm{L}$. Na concentração de $1500 \mu \mathrm{L} / \mathrm{L}$ o óleo essencial de E. citriodora proporcionou inibição de $61 \%$ do $C$. gloeosporioides e $84 \%$ do $C$. musae.

A quantidade e a composição química dos óleos essenciais são influenciadas por diversos fatores, entre eles, a idade da planta, o tipo de tecido, o tipo de solo onde a planta é cultivada e o seu habitat, fatores climáticos, fatores genéticos e horários de coleta do material vegetal (Silva, 2006).

Uma perspectiva para aplicação dos resultados deste trabalho está na elaboração de produtos fitossanitários naturais para o sistema orgânico de produção agropecuária. O Ministério da Agricultura Pecuária e Abastecimento (Brasil, 1999) define os produtos orgânicos como todos aqueles produtos em que se adotam tecnologias que aperfeiçoem o uso de recursos naturais e sócio-econômicos, respeitando a integridade cultural e tendo por objetivo a auto-sustentação no tempo e no espaço, a maximização dos benefícios sociais e a minimização da dependência de energias não renováveis. Assim, devido à eficiência de controle do fungo com o uso de óleos essências, mais trabalhos deverão ser realizadas, testando-se novas concentrações dos óleos essenciais sobre o crescimento miceliano de $C$. gloeosporioides avaliando-se a atividade e estabelecendo concentrações inibitórias seguras dos óleos.

\section{Referências}

Balbi-Peña, M. I.; Becker, A.; Stangarlin, J. R.; Franzener, G.; Lopes, M. C.; Schwan-Estrada, K. R. F. 2006. Controle de
Alternaria solani em tomateiro por extratos de Cúrcuma longa e curcumina - I. Avaliação in vitro. Fitopatologia Brasileira, 1: 1014. Bastos, C. N.; Albuquerque, S. B. 2004. Efeito do óleo de Piper aduncum no controle em pós-colheita de Colletotricum musae em banana. Fitopatologia Brasileira, 29 (5): 555-557.

Brasil, Ministério da Agricultura Pecuária e Abastecimento. 1999. Instrução Normativa $\mathbf{N}^{0}$ 007, de 17 de maio de 1999. Disponível em $<$ http://www.agricultura.gov.br>. Acesso em 15 de junho de 2008.

Campanhola, C.; Bettiol, W. 2003. Métodos alternativos de controle fitossanitário. Embrapa Meio Ambiente, Jaguariúna, Brasil, 279pp.

Canteri, M. G.; Althaus, R. A.; Virgens Filho, J. S.; Giglioti, E. A.; Godoy, C. V. 2001. SASM - Ari: Sistema para análise e separação de médias em experimentos agrícolas pelos métodos Scoft - Knott, Tukey e Duncan. Revista Brasileira de Agrocomputação, 1 (2): 18-24.

Craveiro, A. A.; Fernandes, A. G.; Andrade, C. H. S.; Matos, F. J. A.; Alencar, J. W.; Machado, M. I. L. 1981. Óleos essenciais de Plantas do Nordeste. Editora UFC, Fortaleza, Brasil, 210pp.

Fiori, A. C. G. 2000. Antifungal activity of leaf extrtacts and essentail oils of some medicianl plants againt Didymella bryonice. Jornal of Phytopathology. Disponível em < http://www.ingentaconnect.com/ content/bsc/jph/2000/00000148/F0020007/art00014;jsessionid=12 q4g1dj0j961.alice>. Acesso em 10 de novembro de 2007.

Goodman, L.S.; Gilman, A. 1978. As bases farmacológicas da terapêutica. $5^{\text {a }}$ ed., Guanabara-Koogan, Rio de Janeiro, Brasil, p.883-884.

Grigoletti Júnior, A.; Lau, D. 1999. Crescimento de isolados de Cylindrocladium spathulatum da ervamate, de cinco regiões do estado do Paraná. Boletim de Pesquisa Florestal, 38: 67-75. Disponivel em <http://www.cnpf.embrapa.br/publica/boletim/ boletarqv/boletim38/agrigoletti.pdf.> Acesso em 28 de fevereiro de 2009.

Guimarães, L. G. L.; Souza, P. E.; Cardoso, M. G.. 2007. Estudo do efeito fungitóxico do óleo essencial de Capim-limão (Cymbopogon citratus) sobre Colletotrichum gloeosporioides. 30 ${ }^{\text {a }}$ Reunião Anual da Sociedade Brasileira de Química, Águas de Lindóia, Brasil, v.30, p.1.

Lorenzi, H.; Matos, F. J. A. 2002. Plantas medicinais do Brasil: Nativas e exóticas cultivadas. Instituto Plantarum, Nova Odessa, Brasil, 512pp.

Martins, E. R.; Castro, D. M.; Castellani, D. C.; Evangelista, D. J. 2002. Plantas medicinais. Editora UFV, Viçosa, Brasil, 220pp.

Medice, R., Alves, E.; Assis, R. T.; Júnior, R. G. M; Lopes, E. A. G. L. 2007. Óleos essenciais no controle da Ferrugem Asiática da soja Phakopsora pachyrhizi Syd, \& P. Syd. Ciência agrotecnológica, 31 (1): 83-90.

Pereira, M. C.; Vilela, G. R.; Costa, L. M. A. S. 2006. Inibição do desenvolvimento fúngico através da utilização de óleos essenciais de condimentos. Ciência Agrotecnológica, 30 (4): 731-733.

Pereira, A. J.; Aguiar, L. G.; Silva, D. G.; Vivas, M.; Silveira, S. F. 2007. Inibição in vitro do crescimento micelial de Colletotrichum musae e Colletotrichum gloeosporioides por óleo essencial de Cymbopogom citratus (D.C.) Stapf e Eucalyptus citriodora Hooker. XL Congresso Brasileiro de Fitopatologia. Maringá, Brasil, v.32, p.185. 
Pessoa, M. N. G.; Oliveira, J. C. M.; Innecco, R. 1996. Efeito da tintura de alecrim-pimenta contra fungos fitopatogênicos in vitro. $29^{\circ}$ Congresso de Fitopatologia Brasileira. Brasília, Brasil, vol.21, p.404.

Ribeiro, L. F.; Bedendo, I. P. 1999. Efeito inibitório de extratos vegetais sobre Colletotrichum gloeosporioides - agente causal da podridão de frutos de mamoeiro. Scientia Agricola, 56 (4): $1267-$ 1271.

Ruggiero, C. 1998. Maracujá: Do plantio à colheita. FUNEP, Jaboticabal, Brasil, 388pp.

Salustiano, M. E.; Filho, A. C. F.; Pozza, E. A.; Castro, H. A. 2006. Extratos de candeia (Eremanthus erythropappus (DC.) Macleish) na inibição in vitro de Cylindrocladium scoparium e de quatro espécies de ferrugens. Cerne, 12 (2): 189-193.

Silva, G. S. 2006. Substâncias naturais: Uma alternativa para o controle de doenças. Fitopatologia Brasileira, 31: 259.

Silva, D. M. H.; Bastos, C. N. 2007. Atividade antifúngica de óleos essenciais de espécies de Piper sobre Crinipellis perniciosa, Phytophthora palmivora e Phytophthora capsici. Fitopatologia Brasileira, 32: 143-145.

Stangarlin, J. R.; Schwan-Estrada, K. R. F.; Cruz, M. E. S.; Nozaki, M. H. 1999. Plantas medicinais e o controle alternativo de fitopatógenos. Biotecnologia, Ciência \& Desenvolvimento, 11: $16-21$.
Talamini, V., Stadnik, M. J. 2004. Extratos vegetais e de algas no controle de doenças de plantas. In: Stadnik, M. J.; Talamini, V. (Eds). Manejo ecológico de doenças de plantas. Editora UFSC, Florianópolis, Brasil, p.143-157.

Takatsuka, F. S.; Silva, I. D.; Oliveira, M. F.; Czepak, C.; Oliveira, C. M. A.; Cunha, M. G. 2003. Efeito do óleo essencial de açafrão (Curcuma longa) sobre o desenvolvimento micelial de fungos. $\mathbf{3 6}^{\circ}$ Congresso Brasileiro de Fitopatologia, Uberlândia, Brasil, v.28, p.361.

Viana, F. M. P.; Freire, F. C. O.; Cardoso, J. E.; Vidal, J. C. 2003. Principais doenças do maracujazeiro na região nordeste e seu controle. Comunicado técnico da Emprapa - Fortaleza, CE. Disponível em <http://www.cnpat.embrapa.br/publica/pub/ ComTec/cot_86.pdf>. Acesso em 17 de maio de 2008.

Vivas, M.; Silva, D. G.; Costa, H.; Silveira, S. F.; Pereira, A. J. 2006. Inibição in vitro do crescimento micelial de Colletotrichum acutatum por extrato bruto aquoso e óleo essencial de Cymbopogon citratus (DC) Stapf e Eucalyptus citriodora Hooker. Fitopatologia Brasileira, 31: 265 . 